\title{
Solvent Extraction of Fe(III) from Aqueous Chloride Solution by Cyanex 301 Dissolved in Kerosene
}

\author{
R. K. Biswas ${ }^{1}$, M. R. Ali, M. A. Habib, S. M. A. Salam, A. K. Karmakar, and M. H. Ullah \\ Department of Applied Chemistry and Chemical Engineering, Rajshahi University, Rajshahi-6205, \\ Bangladesh
}

Received 11 October 2010, accepted in final revised form 8 December 2010

\begin{abstract}
The title system has been investigated over a wide range of aqueous acidity. The equilibration time is $1 \mathrm{~h}$. The extraction ratio $(D)$ is independent of [Fe(III)] provided equilibrium [HCl] and [HA] are kept constant. At a constant equilibrium extractant concentration, the $[\mathrm{HCl}]$ dependences are $-1.6, \sim 0$ and -3 in the $[\mathrm{HCl}]$ regions of $>3,2-0.5$ and $<0.3 \mathrm{M}$; respectively; whilst at constant [ $\mathrm{HCl}]$, the [HA] dependence is 3.0. On the other hand, $\left[\mathrm{Cl}^{-}\right]$dependence varies within -0.5 to -3 at constant $[\mathrm{HCl}]$ of $0.3 \mathrm{M}$; whereas its values are $\sim-1$ and $\sim 0.63$ at constant $[\mathrm{HCl}]$ of 3 and $1 \mathrm{M}$, respectively. Based on these results the extraction mechanisms have been suggested to be $\mathrm{FeCl}_{\mathrm{n}}^{(3-\mathrm{n})+}+3 \mathrm{HA}_{(\mathrm{o})} \rightleftharpoons \mathrm{FeA}_{3(\mathrm{o})}$ $+\mathrm{n} \mathrm{Cl}^{-}+3 \mathrm{H}^{+}$in the low $[\mathrm{HCl}]$ region, $\mathrm{FeCl}_{(3-\mathrm{n})}^{\mathrm{n}+}+3 \mathrm{HA}_{(\mathrm{o})}+\mathrm{n} \mathrm{Cl}^{-} \rightleftharpoons \mathrm{FeCl}_{3} \cdot 3 \mathrm{HA}_{(\mathrm{o})}$ in the intermediate [HCl] region and $\mathrm{HFeCl}_{4}+3 \mathrm{HA}_{(\mathrm{o})} \rightleftharpoons \mathrm{FeCl}_{3} \cdot 3 \mathrm{HA}_{(\mathrm{o})}+\mathrm{HCl}$ in the high [HCl] region under investigation. The $K_{e x}$ and $\Delta H$ values have been evaluated. Loading capacity is $5.5 \mathrm{~g} \mathrm{Fe}(\mathrm{III}) / 100 \mathrm{~g}$ Cyanex 301. The stripping can be made effective by a mixture of $6 \mathrm{M}$ $\mathrm{H}_{2} \mathrm{SO}_{4}$ and $1 \mathrm{M} \mathrm{Na}_{2} \mathrm{C}_{2} \mathrm{O}_{4}$.
\end{abstract}

Keywords: Extraction equilibrium; Fe(III) extraction; Cyanex 301; chloride medium.

(c) 2011 JSR Publications. ISSN: 2070-0237 (Print); 2070-0245 (Online). All rights reserved. doi:10.3329/jsr.v3i1.6263 J. Sci. Res. 3 (1), 97-109 (2011)

\section{Introduction}

The green viscous bis-(2,4,4-trimethylpentyl)dithiophosphinic acid (trade name being Cyanex 301, $\mathrm{C}_{16} \mathrm{H}_{34} \mathrm{PS}_{2} \mathrm{H}, \mathrm{HA}$ ) has been introduced as an extractant in the last decade of the $20^{\text {th }}$ century by American Cyanamide Co. and Cytec Canada Inc. Supplied sample contains $77.2 \%$ bis (2,4,4-trimethylpentyl)dithiophosphinic acid and there is still no way to purify it more. Some physical constants of the supplied Cyanex 301 are given elsewhere [1]. The vapor pressure osmometry (VPO) analysis indicates Cyanex 301 is monomeric [2].

Iron-bearing compounds are often present as gangue materials in ores of many common valuable metals. Therefore, it becomes necessary to separate iron from a leached

\footnotetext{
${ }^{1}$ Corresponding author: rkbiswas53@yahoo.com
} 
solution of an ore for the production of a pure metal hydrometallurgically and this can be carried out effectively by the solvent extraction technique.

The solvent extractions of Fe(III) by various organophosphorous compound have been investigated widely. The works with tributylphosphate (TBP), dibutylphosphate (DBP), dodecylphosphoric acid etc. have been cited by Sekine and Hasegawa [3]. Di-2ethylhexylphosphoric acid (D2EHPA) has been used widely for the extraction of Fe(III) [4-15]. Mono-2-ethylhexylphosphoric acid (M2EHPA) has been used for the same by several workers [16,17]. The phosphinic acid derivative, bis-2,4,4trimethylpentylphosphinic acid (abbreviated as BTMPPA, commercially known as Cyanex 272) has also been used for the extraction of Fe(III) [18-21]. Using Cyanex 301 as an extractant, the extractions of Ti(IV) [1], Zn(II) [22], In(III) [23], Sb(III), Bi(III), Pb(II) and $\mathrm{Sn}(\mathrm{IV})$ [24], $\mathrm{Cu}(\mathrm{II})$ [25], $\mathrm{Co}(\mathrm{II})$ and Ni(II) [26], Ag (I) [27], $\mathrm{Zr}(\mathrm{IV})$ [28], etc. have been reported. Although there is a report [2] on the preliminary extraction behaviors of $\mathrm{Fe}(\mathrm{III}), \mathrm{Zn}(\mathrm{II}), \mathrm{Cu}(\mathrm{II}), \mathrm{Co}(\mathrm{II})$ and $\mathrm{Ni}(\mathrm{II})$ from sulphate media by Cyanex 301 and Cyanex 302, the thorough mechanistic study on the extraction of Fe(III) from any medium including chloride medium by Cyanex 301 is lacking in the literature. This work represents a thorough mechanistic study on the $\mathrm{Fe}(\mathrm{III})$ - $\mathrm{Cl}^{-}$- Cyanex 301- kerosene system.

\section{Experimental}

\subsection{Reagents}

Cyanex 301 was donated by Cytec Canada Inc. Kerosene was obtained from the local market and distilled to collect the fraction distilling over $200-260^{\circ} \mathrm{C}$. It was colorless and mostly aliphatic in nature. Ferric chloride (Loba Chemie, 99\%) was used as a source of $\mathrm{Fe}(\mathrm{III})$. All the other chemicals were of reagent grade and used as received.

\subsection{Analytical}

The concentration of $\mathrm{Fe}(\mathrm{III})$ in the aqueous phase was determined by the thiocyanate method [29] at $480 \mathrm{~nm}$ using a WPA S104 Spectrophotometer. The standard solution of $\mathrm{Fe}(\mathrm{III})$ was prepared by dissolving $0.846 \mathrm{~g} \mathrm{~A}$. R. $\mathrm{FeNH}_{4}\left(\mathrm{SO}_{4}\right)_{2}$ in $1 \mathrm{~L} 0.1 \mathrm{M} \mathrm{H}_{2} \mathrm{SO}_{4}$ solution $(1 \mathrm{~mL}=0.1 \mathrm{mg} \mathrm{Fe}(\mathrm{III})$ ). The acidity of the aqueous phase was adjusted by the addition of $\mathrm{HCl}$; whilst, $\mathrm{Cl}^{-}$concentration by $\mathrm{NaCl}$ addition.

\subsection{Extraction procedure}

A stock solution of $\mathrm{FeCl}_{3}(1 \mathrm{~L})$ was prepared to contain $10.01 \mathrm{~g}$ Fe(III) (0.179 M), $0.12 \mathrm{M}$ $\mathrm{H}^{+}$and $0.657 \mathrm{M} \mathrm{Cl}^{-}$. This solution was used to prepare the aqueous phases containing different amounts of $\mathrm{H}^{+}, \mathrm{Cl}^{-}$and $\mathrm{Fe}(\mathrm{III})$ for extraction. The extraction procedures are given elsewhere $[4,12,15]$. Equal aliquots of organic and aqueous phases (20 mL each) were taken in an $125 \mathrm{~mL}$ reagent bottle and agitated for a predetermined time $(1 \mathrm{~h})$ at 303 
$\mathrm{K}$ in a thermostatic water bath. After mechanical shaking, the phases were allowed to settle, separated and the aqueous phase was analyzed for its Fe(III) content colorimetrically as mentioned above. The concentration of Fe(III) in the organic phase was calculated from the difference. The value of the distribution or extraction ratio $(D)$ was calculated as the ratio of the concentration of Fe(III) in the organic phase to that existing in the aqueous phase at equilibrium.

\subsection{Loading procedure}

Loadings of $\mathrm{Fe}(\mathrm{III})$ in $0.177,0.147$ and $0.118 \mathrm{M}$ Cyanex 301 solutions were carried out by vigorous contact of these phases $(50 \mathrm{~mL})$ separately and repeatedly with fresh aqueous solutions (containing $1 \mathrm{~g} / \mathrm{L} \mathrm{Fe}(\mathrm{III})$; and $0.3,1.0$ and $3.0 \mathrm{M} \mathrm{HCl}$ for $0.177,0.147$ and 0.118 $\mathrm{M}$ extractant systems, respectively) of same volume until the organic phases were saturated with Fe(III). After each contact, the phases were disengaged and the aqueous phases were analyzed for their $\mathrm{Fe}(\mathrm{III})$ contents. The amount of $\mathrm{Fe}^{3+}$ transferred into the organic phase for each contact was calculated from the difference and then the cumulative concentrations of $\mathrm{Fe}(\mathrm{III})$ in the organic phase (cumulative $[\mathrm{Fe}(\mathrm{III})]_{(\mathrm{o})}$, g/L ) after each stage of contact were determined.

\subsection{Stripping procedure}

The loaded organic phases obtained above were diluted separately with kerosene so that the resultant solutions contained $1 \mathrm{~g} / \mathrm{L} \mathrm{Fe(III)} \mathrm{as} \mathrm{complex} \mathrm{and} \mathrm{practically} \mathrm{no} \mathrm{free}$ extractant. These solutions were used to study stripping of various Fe(III)-HA entities existing in the organic phase depending on aqueous acidities used in extractions. Strippings were performed by $1 \mathrm{M}$ and $6 \mathrm{M} \mathrm{H}_{2} \mathrm{SO}_{4}, \mathrm{HNO}_{3}, \mathrm{HCl}$ and $\mathrm{HClO}_{4}$ acid solutions together with a mixture of $6 \mathrm{M} \mathrm{H}_{2} \mathrm{SO}_{4}$ and $1 \mathrm{M} \mathrm{Na}_{2} \mathrm{C}_{2} \mathrm{O}_{4}$. In stripping, $10 \mathrm{~mL}$ of $\mathrm{Fe}(\mathrm{III})$ loaded organic phase was equilibrated with an equal aliquot of each of the above acid solution for $1 \mathrm{~h}$ at $303 \mathrm{~K}$. After equilibration, the phases were settled, disengaged and the aqueous phase was analyzed for Fe(III) content. In stage-wise stripping, the organic phase was recycled with equal aliquot of fresh aqueous phase.

\section{Results and Discussion}

Preliminary experiments show that the concentration ratio $\left([\mathrm{Fe}(\mathrm{III})]_{(\mathrm{o})} /[\mathrm{Fe}(\mathrm{III})]_{(\mathrm{aq})}\right)$ increases almost exponentially with increasing phase contact time up to 45 min for the investigated system which indicates that the equilibration time for the system is $45 \mathrm{~min}$. In subsequent experiments, the phase contact time of $1 \mathrm{~h}$ was allowed to ensure equilibration

under different experimental conditions. Previously, it has been reported that equilibration times for the extraction of $\mathrm{Fe}(\mathrm{III})$ from chloride medium by analytical grade D2EHPA[12], technical grade D2EHPA [15], Cyanex 272 [20] and Cyanex 302 [30] in kerosene are $50 \mathrm{~min}$. So the equilibration time for the extraction of Fe(III) from chloride 
medium by Cyanex 301 in kerosene is similar to those by other acidic organo-phosphoric and phosphinic acid derivatives in kerosene.

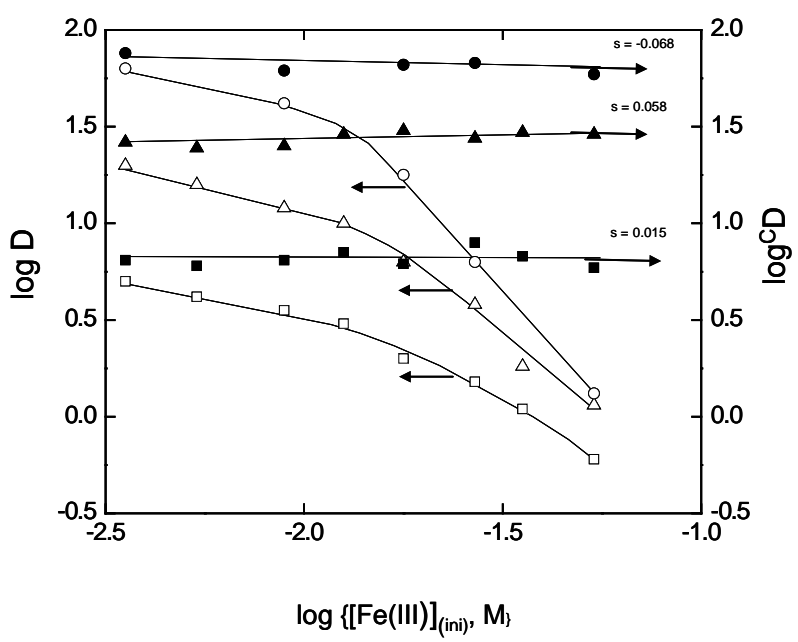

Fig. 1. Dependence of extraction ratio on initial $[\mathrm{Fe}(\mathrm{III})]$ in the aqueous phase. Equilibration time $=1 \mathrm{~h}$, Temp. $=303 \mathrm{~K},[\mathrm{HA}]_{(\mathrm{o}, \text { ini) }}=0.059 \mathrm{M} ;(\bigcirc, \mathbf{O}),[\mathrm{HCl}]_{(\text {(ini) }}=0.3 \mathrm{M}(\triangle, \boldsymbol{\Delta}),[\mathrm{HCl}]_{(\text {(ini) }}=1.0 \mathrm{M} ;(\square, \boldsymbol{\square}),[\mathrm{HCl}]_{(\mathrm{ini})}=5 \mathrm{M}$. Open symboled plots are at constant initial HA and $\mathrm{HCl}$ concentrations; whilst closed symboled plots are at constant equilibrium concentrations of $\mathrm{HA}$ and $\mathrm{HCl}$ considered equaling to the initial $\mathrm{HA}$ and $\mathrm{HCl}$ concentrations, respectively.

Fig. 1 shows the variations of $D$ with initial [Fe(III)] (3.72 $\mathrm{mM}-64.87 \mathrm{mM})$ while extracted by $0.059 \mathrm{M}$ Cyanex 301 at $0.3,1$ and $5 \mathrm{M} \mathrm{HCl}$ in log-log scale. It is found that in all cases the distribution ratio is decreased extensively with the increase of initial $\mathrm{Fe}(\mathrm{III})$ concentration in the aqueous phase at the cited constant initial concentrations of $\mathrm{HCl}$ and $\mathrm{HA}$; particularly at higher concentration region of Fe(III). This type of behavior indicates the formation of non-extractable $\mathrm{Fe}(\mathrm{III})-\mathrm{Cl}^{-}$species in the aqueous phase or the scarcity of extractant at higher Fe(III) concentration. However, this statement will be valid only when the equilibrium acidity and extractant concentration remained constant [31]. Since relatively high concentration of $\mathrm{HCl}$ has been used in the study, there will be little change in its concentration on equilibration. In contrast, the equilibrium concentration of free HA will be decreased from the initial concentration to a greater extent on extracting large amounts of $\mathrm{Fe}(\mathrm{III})$ particularly from concentrated $\mathrm{Fe}(\mathrm{III})$ solutions. On considering the extracted species being $1: 3 \mathrm{Fe}(\mathrm{III})$ - HA complexes (as will be seen latter), the necessary corrections of $\log D$ values to get $\log { }^{C} D$ values have been made (where, ${ }^{C} D$ is the corrected $D$ values at constant equilibrium $\mathrm{HCl}$ and $\mathrm{HA}$ concentration equaling to constant initial $\mathrm{HCl}$ and $\mathrm{HA}$ concentrations) as follows: $\log { }^{C} D=\log D+3\left[\log [\mathrm{HA}]_{(\mathrm{o}, \mathrm{ini})}\right.$ $\left.-\log \left([\mathrm{HA}]_{(\mathrm{o}, \text { ini })}-3[\mathrm{Fe}(\mathrm{III})]_{(\mathrm{o}, \mathrm{eq})}\right)\right]-x\left[\log [\mathrm{HCl}]_{(\mathrm{ini})}-\log [\mathrm{HCl}]_{(\mathrm{ini})}-\mathrm{x}[\mathrm{Fe}(\mathrm{III})]_{(\mathrm{o}, \mathrm{eq})}\right]$; whence $x$ is $[\mathrm{HCl}]$ dependence and it depends on $[\mathrm{HCl}]$ region: $x=-3,0$ and -1.6 at low, intermediate and high concentration regions of $\mathrm{HCl}$, respectively. The $\log { }^{C} D$ vs. $\log$ $[\mathrm{Fe}(\mathrm{III})]_{\text {(ini) }}$ plots are also given in Fig. 1. 
The plots are straight lines with almost zero slopes (the least squares slopes are -0.068 , 0.058 and 0.085 for $0.3,1.0$ and $5.0 \mathrm{M} \mathrm{HCl}$ systems, respectively). It is therefore concluded that the extraction ratio is independent of $\mathrm{Fe}(\mathrm{III})$ concentration in the aqueous phase provided the equilibrium $[\mathrm{HCl}]$ and $[\mathrm{HA}]$ are kept constant; and this behavior is in consistent with the principle of solvent extraction. Results also suggest that the percentages of various $\mathrm{Fe}(\mathrm{III})-\mathrm{Cl}^{-}$species are not changed with $\mathrm{Fe}(\mathrm{III})$ concentration provided sufficient $\mathrm{Cl}^{-}$exists there, which is in accord with Gamlen and Jordan [32]. They suggested that the percentages of various $\mathrm{Fe}(\mathrm{III})-\mathrm{Cl}^{-}$species existing in the aqueous phase were a function of $\mathrm{Cl}^{-}$concentration in the system, but not of [Fe(III)].

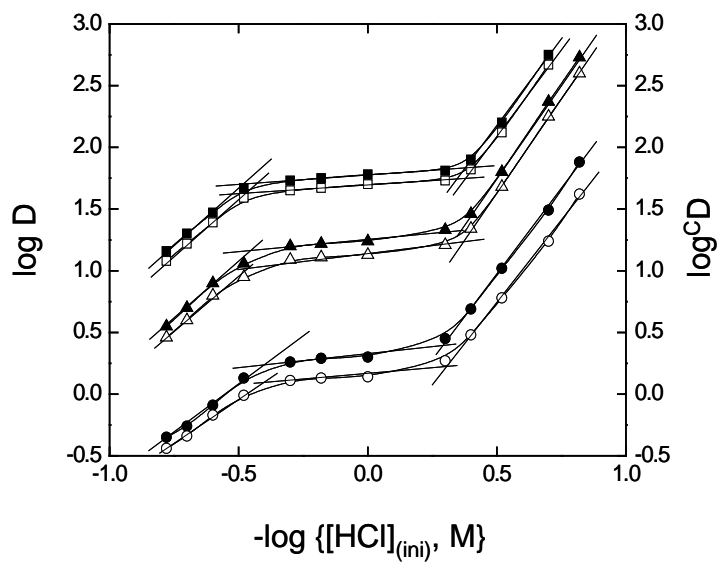

Fig. 2. Dependence of extraction ratio on $[\mathrm{HCl}]$ in the aqueous phase: $\log D$ vs. $\log \{[\mathrm{HCl}], \mathrm{M}\}$ (open symbol) and $\log { }^{C} D$ vs. $\log \{[\mathrm{HCl}], \mathrm{M}\}$ (closed symbol) plots. $[\mathrm{Fe}(\mathrm{III})]_{\text {(ini) }}=0.2 \mathrm{~g} / \mathrm{L}$, Temp. $=303 \mathrm{~K}$, Equilibration time $=$ $1 \mathrm{~h},[\mathrm{HA}]_{(\mathrm{o}, \text { ini) }}=0.059 \mathrm{M}$ (circles), 0.118 (triangles) and $0.177 \mathrm{M}$ (squares). At $[\mathrm{HCl}]<0.4 \mathrm{M}$; $(\mathrm{O})$, l. s. slope, $s=$ 2.59, l. s. intercept $=-0.541 ;(\triangle), s=3.02, I=0.123 ;(\square), s=2.85, I=0.664 ;(\bigcirc), s=2.73, I=-0.392 ;(\boldsymbol{\Delta}), s$ $=3.05, I=0.232 ;(\mathbf{\square}), s=2.35, I=0.744$; within $[\mathrm{HCl}]=0.7-2.0 \mathrm{M} ;(\bigcirc), s=0.10, I=0.142 ;(\triangle), s=0.20$, $I=1.144 ;(\square), s=0.13, I=1.693 ;(\bigcirc), s=0.13, I=0.304 ;(\boldsymbol{\Delta}), s=0.22, I=1.257 ;(\square), s=0.13, I=1.779$; and at $[\mathrm{HCl}]>3.0 \mathrm{M} ;(\bigcirc), s=1.46, I=0.695 ;(\triangle), s=1.66, I=1.764 ;(\square), s=1.70, I=2.407 ;(\bullet), s=1.62, I$ $=0.896 ;(\mathbf{\Delta}), s=1.72, I=1.902 ;(\mathbf{\square}), s=1.70, I=2.487$.

The variations of $D$ and ${ }^{C} D$ on $\mathrm{HCl}$ concentrations are shown in Fig. 2 as $\log D$ and $\log { }^{C} D$ vs $-\log \{[\mathrm{HCl}], \mathrm{M}\}$ plots for $0.059,0.118$ and $0.177 \mathrm{M}$ constant initial and equilibrium Cyanex 301 concentrations, respectively. In all cases, gradual decrease in [HCl] from $6 \mathrm{M}$, the $\log D$ or $\log { }^{C} D$ value is first increased (up to $3 \mathrm{M} \mathrm{HCl}$ ), then it remains almost unchanged (within $2 \sim 0.7 \mathrm{M} \mathrm{HCl}$ ) and finally, the value is again increased linearly (beyond $0.5 \mathrm{M} \mathrm{HCl}$ ). This peculiar type of curve in both type of plotting (also noticed earlier during extraction of Fe(III) from $\mathrm{Cl}^{-}$medium by D2EHPA in kerosene [12]) has a slope of about $\sim 1.6, \sim 0.15$ and $\sim 3$, respectively, in the higher $(>3$ $\mathrm{M})$, intermediate $(2 \sim 0.7 \mathrm{M})$ and lower $(<0.5 \mathrm{M})$ concentration regions of $\mathrm{HCl}$. The intercepts of the $\log { }^{C} D$ vs $-\log [\mathrm{HCl}]$ curves at higher (> $3 \mathrm{M}$ ), intermediate and lower $(<0.3 \mathrm{M})$ acid concentration regions are 0.896, 0.304 and $-0.392 ; 1.902,1.257$ and 0.232; and 2.487, 1.779 and 0.744 for $0.059,0.118$ and 0.177 M Cyanex 301 systems, 
respectively. Therefore, in both higher and lower $\mathrm{HCl}$ concentration regions, $\mathrm{HCl}$ or $\mathrm{H}^{+}$is liberated by extraction reaction. Within $0.5-2.0 \mathrm{M} \mathrm{HCl}$ region, $\mathrm{HCl}$ or $\mathrm{H}^{+}$is not produced or utilized during extraction.

Fig. 3 represents the $\log { }^{C} D$ vs. $\log \left\{[\mathrm{HA}]_{(0, e q)}, M\right\}$ plots for 5.0, 1.0 and $0.3 \mathrm{M}$ constant $\mathrm{HCl}$ systems. The values of $\log [\mathrm{HA}]_{(\mathrm{o}, \mathrm{eq})}$ have been calculated as: $\log [\mathrm{HA}]_{(\mathrm{o}, \mathrm{eq})}=$ $\log \left([\mathrm{HA}]_{(0, \text { ini })}-3[\mathrm{Fe}(\mathrm{III})]_{(\mathrm{o}, \mathrm{eq})}\right)$ after getting an idea on extractant dependence to be 3 from $\log D$ vs. $\log [\mathrm{HA}]_{(\mathrm{o}, \text { ini) }}$ plots (not shown). Plots are straight lines with slope of $\sim 3$ (2.81- 2.91). The intercepts of $\log { }^{C} D$ vs. $\log [\mathrm{HA}]_{(\mathrm{o}, \mathrm{eq})}$ plots are $4.514,3.875$ and 3.352 for $0.3,1.0$ and $5.0 \mathrm{M} \mathrm{HCl}$ systems, respectively. It is concluded from these results that the extractant dependence remains unaltered over the entire $\mathrm{HCl}$ concentration range used in this study and the extractant concentration functionality is very high for this system. Whatever may be the $[\mathrm{HCl}]$ in the system, the extractant dependence is always 3; i.e., 3 moles of extractant are attached to $1 \mathrm{~g}$ ion of Fe(III) to form 1 mole of extractable species.

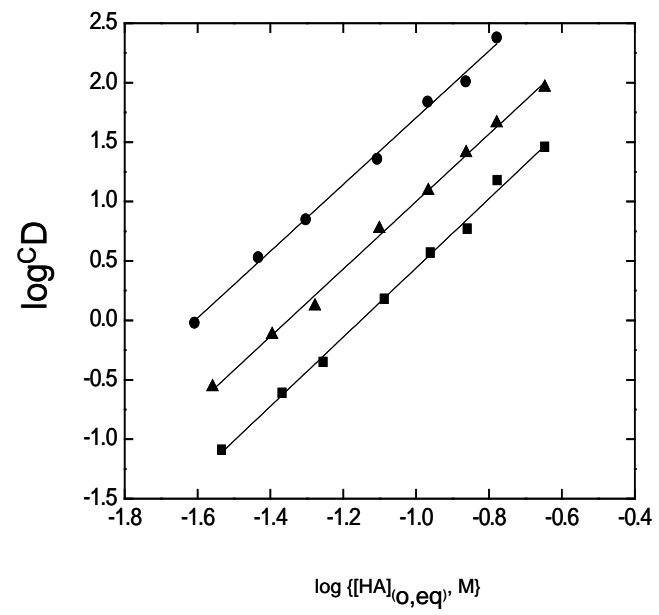

Fig. 3. Dependence of extraction ratio on [HA] in the organic phase: $\log { }^{C} D$ vs. $\log \{[\mathrm{HA}]$, M $\}$ plots. Temp. $=$ $303 \mathrm{~K}$, Equilibration time $=1 \mathrm{~h},[\mathrm{Fe}(\mathrm{III})]_{(\mathrm{ini})}=0.2 \mathrm{~g} / \mathrm{L} ;(\mathbf{O}),[\mathrm{HCl}]_{(\mathrm{ini})}=0.3 \mathrm{M}, s=2.81, I=4.514 ;(\mathbf{\Delta}),[\mathrm{HCl}]_{(\mathrm{ini})}$ $=1.0 \mathrm{M}, s=2.84, I=3.875 ;(\boldsymbol{\square}),[\mathrm{HCl}]_{(\mathrm{ini})}=5.0 \mathrm{M}, s=2.91, I=3.352$.

Fig. 4 shows the dependence of extraction ratio on chloride ion concentration as log ${ }^{C} D$ vs. $-\log \left\{\left[\mathrm{Cl}^{-}\right], \mathrm{M}\right\}$ plots at $0.3,1.0$ and $3.0 \mathrm{M}\left[\mathrm{H}^{+}\right]$systems whence extracted by 0.059 M Cyanex 301 solution. In no case straight line is obtained. At 0.3 and $3.0 \mathrm{M}\left[\mathrm{H}^{+}\right]$, the extraction ratio is decreased with increasing $\left[\mathrm{Cl}^{-}\right]$, but the extent of decrement depends on constant $\left[\mathrm{H}^{+}\right]$used in the system and the $\left[\mathrm{Cl}^{-}\right]$region as well. From this result, it can be concluded that at least on a qualitative basis $\mathrm{Cl}^{-}$is liberated by the extraction reaction when the $[\mathrm{HCl}]$ is kept either high or low. On the other hand, at intermediate $\left[\mathrm{H}^{+}\right]$region $(\sim 1.0 \mathrm{M})$, the extraction ratio is increased with increasing $\left[\mathrm{Cl}^{-}\right]$; so that $\mathrm{Cl}^{-}$is added to the existing $\mathrm{Fe}(\mathrm{III})-\mathrm{Cl}^{-}$species in the aqueous phase to form the extractable species. 


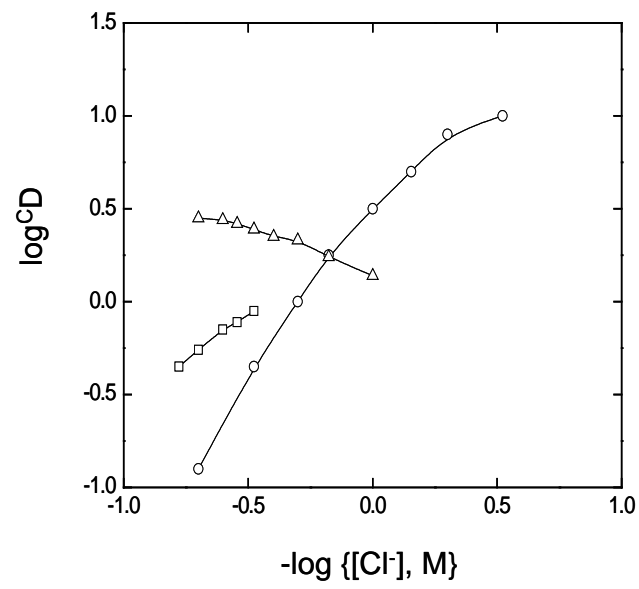

Fig. 4. Dependence of extraction ratio on $\left[\mathrm{Cl}^{-}\right]$in the aqueous phase: $\log { }^{C} D$ vs. $-\log \left\{\left[\mathrm{Cl}^{-}\right], \mathrm{M}\right\}$ plots. Temp. $=$ $303 \mathrm{~K}$, Equilibration time $=1 \mathrm{~h},[\mathrm{Fe}(\mathrm{III})]_{(\mathrm{ini})}=0.2 \mathrm{~g} / \mathrm{L},[\mathrm{HA}]_{(\mathrm{o}, \text { ini })}=0.059 \mathrm{M} ;(\mathrm{O}),\left[\mathrm{H}^{+}\right]=0.3 \mathrm{M}, \mathrm{s}=\sim(2.5-0.4)$; $(\triangle),\left[\mathrm{H}^{+}\right]=1.0 \mathrm{M}, \mathrm{s}=\sim[(-0.1)-(-0.5)] ;(\square),\left[\mathrm{H}^{+}\right]=3.0 \mathrm{M}, \mathrm{s}=\sim(1.2-0.8)$.

The literature reports [12, 32] indicate that the existing $\mathrm{Fe}(\mathrm{III})$ species in $0.2 \mathrm{M} \mathrm{Cl}^{-}$ medium are $12.9 \% \mathrm{Fe}^{3+}$, $38.1 \% \mathrm{FeCl}^{2+}, 35.6 \% \mathrm{FeCl}_{2}{ }^{+}$and $13.4 \% \mathrm{FeCl}_{3}$; whereas in 0.4 $\mathrm{M} \mathrm{Cl}^{-}$medium, the respective percentages are changed to 7.5, 27, 42.7 and $22.8 \%$. The $\left[\mathrm{H}^{+}\right]$and $[\mathrm{HA}]_{(\mathrm{o})}$ dependences of -3 and 3 , respectively, together with variable negative $\left[\mathrm{Cl}^{-}\right]$dependences suggest the following extraction reaction in the lower $[\mathrm{HCl}]$ region used in this investigation:

$$
\mathrm{FeCl}_{\mathrm{n}}^{(3-\mathrm{n})+}+3 \mathrm{HA}_{(\mathrm{o})} \rightleftharpoons \mathrm{FeA}_{3(\mathrm{o})}+3 \mathrm{H}^{+}+\mathrm{n} \mathrm{Cl}^{-}
$$

where, $0 \leq \mathrm{n} \leq 3$. As the value of $\mathrm{x}$ (average number of $\mathrm{Cl}^{-}$associated with $\mathrm{Fe}$ (III) in the aqueous phase; e.g. $(0.129 \times 0+0.381 \times 1+0.356 \times 2+0.134 \times 3) \div 4=0.374$ at $\left[\mathrm{Cl}^{-}\right]=0.2$ $\mathrm{M}$ and $(0.075 \times 0+0.27 \times 1+0.427 \times 2+0.228 \times 3) \div 4=0.452$ at $\left.\left[\mathrm{Cl}^{-}\right]=0.4 \mathrm{M}\right)$ increases with increasing $\left[\mathrm{Cl}^{-}\right]$, the experimental $\left[\mathrm{Cl}^{-}\right]$dependence (negative slope of $\log { }^{C} D$ vs. - $\log$ $\left[\mathrm{Cl}^{-}\right]$) increases with increasing $\left[\mathrm{Cl}^{-}\right]$in the system. Therefore, Eq. (1) can explain the experimental data well.

On the other hand, within $[\mathrm{HCl}]$ of $0.5-2.0 \mathrm{M}$, the predominant aqueous species of $\mathrm{Fe}(\mathrm{III})$ is $\mathrm{FeCl}_{3}$ (e.g. the fractions of $\mathrm{Fe}^{3+}, \mathrm{FeCl}^{2+}, \mathrm{FeCl}_{2}{ }^{+}$and $\mathrm{FeCl}_{3}$ are 0.02, 0.158, 0.392 and 0.43 , respectively, at $[\mathrm{HCl}]=1.0 \mathrm{M}$; and $0.00,0.10,0.276$ and 0.624 , respectively, at $[\mathrm{HCl}]=2.0 \mathrm{M})$ and so $[\mathrm{HCl}],[\mathrm{HA}]$ and $\left[\mathrm{Cl}^{-}\right]$dependences of $\sim 0,3$ and about 0.63 suggest the following extraction reaction in the intermediate $[\mathrm{HCl}]$ region:

$$
\mathrm{FeCl}_{(3-\mathrm{n})}^{\mathrm{n}+}+3 \mathrm{HA}_{(\mathrm{o})}+\mathrm{n} \mathrm{Cl}^{-} \rightleftharpoons \mathrm{FeCl}_{3} \cdot 3 \mathrm{HA}_{(\mathrm{o})}
$$

where, $0 \leq \mathrm{n} \leq 3$. As the value of $\mathrm{n}$ (average number of $\mathrm{Cl}^{-}$short of 3 associated with $\mathrm{Fe}$ (III) in the aqueous phase (e.g. $(0.02 \times 3+0.158 \times 2+0.392 \times 1+0.43 \times 0) \div 4=0.192$ at $\left[\mathrm{Cl}^{-}\right]=1 \mathrm{M}$ and $(0 \times 3+0.1 \times 2+0.276 \times 1+0.624 \times 0) \div 4=0.119$ at $\left.\left[\mathrm{Cl}^{-}\right]=2 \mathrm{M}\right)$ decreases with increasing $\left[\mathrm{Cl}^{-}\right]$, the experimental $\left[\mathrm{Cl}^{-}\right]$dependence (negative slope of $\log { }^{C} D$ vs. - 
$\left.\log \left[\mathrm{Cl}^{-}\right]\right)$decreases with increasing $\left[\mathrm{Cl}^{-}\right]$in the system. Therefore, Eq. (2) can explain the experimental data obtained around $1 \mathrm{M} \mathrm{HCl}$ medium.

The ion pair, $\mathrm{HFeCl}_{4}$ starts to form in the $3 \mathrm{M} \mathrm{Cl}^{-}$medium [12, 32] and so in the higher $[\mathrm{HCl}]$ region, the extraction occurs via the following reaction:

$$
\mathrm{HFeCl}_{4}+3 \mathrm{HA}_{(\mathrm{o})} \rightleftharpoons \mathrm{FeCl}_{3} \cdot 3 \mathrm{HA}_{(\mathrm{o})}+\mathrm{HCl}
$$

Eq. (3) satisfies the extractant dependence of 3 but it indicates the HCl-dependence of -1. However, experimentally [ $\mathrm{HCl}]$-dependence of about -1.6 is obtained. This might be due to the presence of $\mathrm{H}_{\mathrm{x}} \mathrm{FeCl}_{3+x}(x>1)$ in the medium at still higher $[\mathrm{HCl}$ ] region. From the foregoing discussion, it is revealed that the extracted species is $\mathrm{FeA}_{3}$ at the lower $[\mathrm{HCl}]$ region and that at intermediate and higher $[\mathrm{HCl}]$ region is $\mathrm{FeCl}_{3} .3 \mathrm{HA}$.

The effect of temperature on the extraction has been studied in the range of 15 to $40^{\circ} \mathrm{C}$. Fig. 5 shows $\log { }^{C} D$ vs. $(1 / T) \times 10^{3}, \mathrm{~K}^{-1}$ plots for extractions from $0.3,1.0$ and 5.0 $\mathrm{M}[\mathrm{HCl}]$ medium by $0.059 \mathrm{M}$ Cyanex 301 . It is found that the extraction ratio is increased with increasing temperature. The plots are straight lines with slopes equaling to -2265, 604 and - 814 giving $\Delta H$ values of $45.2,12.0$ and $16.2 \mathrm{~kJ} \mathrm{~mol}^{-1}$, respectively, for $0.3,1.0$ and $5.0 \mathrm{M} \mathrm{HCl}$ systems. The positive $\Delta H$ values indicate that the extraction reactions represented by Eqs. (1) to (3) are exothermic in nature and its high value at $0.3 \mathrm{M} \mathrm{HCl}$ system supports the formation of extractable species by chelation; whereas, low values at intermediate and higher [ $\mathrm{HCl}]$ levels support the formation of extractable species by solvation.

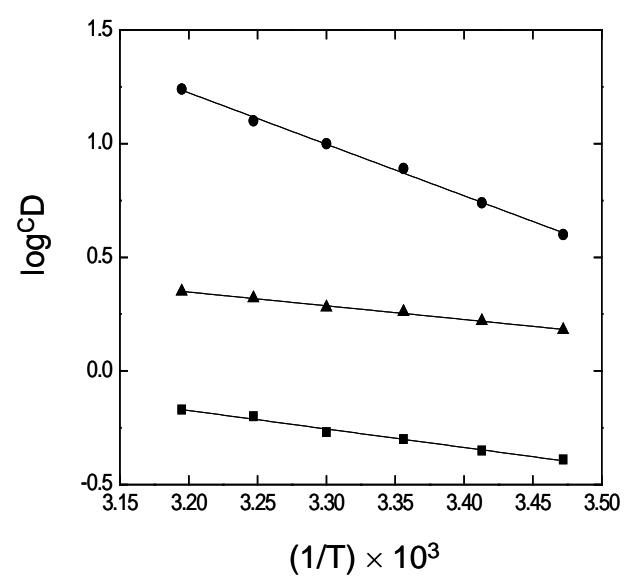

Fig. 5. Dependence of extraction ratio on temperature: $\log { }^{\mathrm{C}} D$ vs. $(1 / \mathrm{T}) \times 10^{3}, \mathrm{~K}^{-1}$ plots. Equilibration time $=1 \mathrm{~h}$, $[\mathrm{Fe}(\mathrm{III})]_{(\mathrm{ini})}=0.2 \mathrm{~g} / \mathrm{L},[\mathrm{HA}]_{(\mathrm{o}, \text { ini })}=[\mathrm{HA}]_{(\mathrm{o}, \text { ini })}=0.059 \mathrm{M} ;(\mathbf{O}),[\mathrm{HCl}]_{(\mathrm{o}, \text { ini })}=0.3 \mathrm{M}, s=-2265 ;(\boldsymbol{\Delta}),[\mathrm{HCl}]_{(\mathrm{o}, \text { ini })}=1.0$ $\mathrm{M}, s=-604 ;(\mathbf{\square}),[\mathrm{HCl}]_{(\mathrm{o}, \text { ini })}=5.0 \mathrm{M}, s=-814$.

The loading capacity, defined as the maximum amount of metal ion in gram extracted per $100 \mathrm{~g}$ of a pure extractant, is a very important factor for an extractant's commercial applicability. High loading capacity is desirable for a particular extractant-metal ion 
system. Moreover, the species extracted at high loading may be easily converted to pure (usually solid) complexes for its structure determination by chemical and instrumental analyses. The cumulative $[\mathrm{Fe}(\mathrm{III})]_{(\mathrm{o})}$ vs. contact number plots are given in Fig. 6 (when the organic phases were repeatedly contracted with fresh aqueous phases) at three different sets of experimental parameters. It is indicated that most of the $\mathrm{Fe}(\mathrm{III})$ existing in the aqueous phase is extracted into the organic phase up to the $4^{\text {th }}$ contact and then the uptake by Cyanex 301 is gradually decreased to zero at the $8^{\text {th }}$ contact in all three cases. It is found from Fig. 6 that $0.177 \mathrm{M}($ at $[\mathrm{HCl}]=0.3 \mathrm{M}), 0.147 \mathrm{M}($ at $[\mathrm{HCl}=1.0 \mathrm{M})$ and 0.118 $\mathrm{M}($ at $[\mathrm{HCl}]=3.0 \mathrm{M})$ Cyanex 301 solution can extract maximum of 3.3, 2.7 and $2.195 \mathrm{~g}$ $\mathrm{Fe}(\mathrm{III}) / \mathrm{L}$ (0.05908, 0.04834 and $0.03930 \mathrm{M} \mathrm{Fe}(\mathrm{III})$ per L organic phase), respectively. These values indicate that the loading capacities of Cyanex 301 towards Fe(III) at [HCl] of 0.3 M, 1.0 M and 3.0 M are 5.5, 5.4 and 5.49 g Fe(III)/100 g Cyanex 272, respectively; in comparison to $8.38 \mathrm{~g} \mathrm{Fe}(\mathrm{III}) / 100 \mathrm{~g}$ analytical grade D2EHPA [12], $13.13 \mathrm{~g} \mathrm{Fe(III)/} 100$ g technical grade D2EHPA [15], 9.6 g Fe(III)/100 g Cyanex 272 [20] and $29.41 \mathrm{~g} \mathrm{Fe(III)/}$ 100 g Cyanex 302 [30]. Moreover, the maximum loading capacity suggests that the extracted complex should have a Cyanex 301/Fe(III) ratio of 3 in the complex $\left(\mathrm{FeA}_{3}\right.$ or $\mathrm{FeCl}_{3} .3 \mathrm{HA}$ ), which has already been established by the mechanistic study. So the extraction mechanism at a certain aqueous acidity is not changed with the extent of loading.

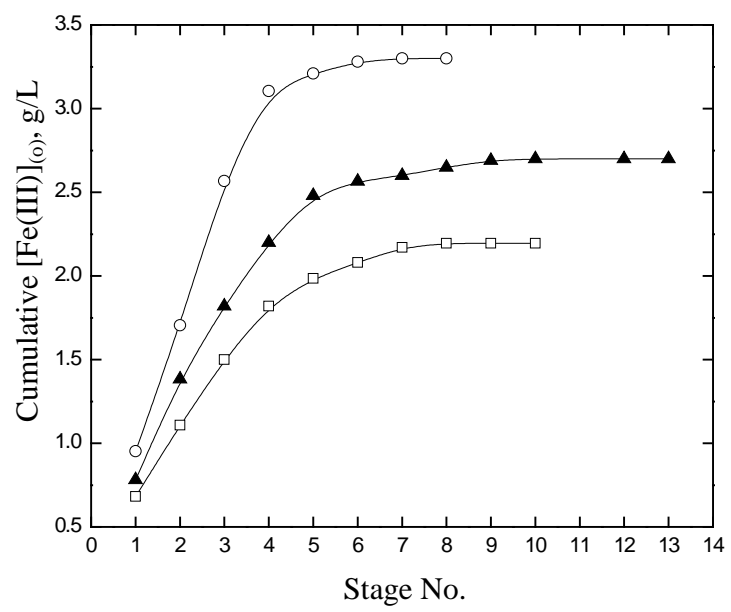

Fig. 6. Loading of organic phase by Fe(III). Temp. $=303 \mathrm{~K}$, Equilibration time $=1 \mathrm{~h}$ (in each stage), $[\mathrm{Fe}(\mathrm{III})]_{(\mathrm{ini})}=1 \mathrm{~g} / \mathrm{L},(\bigcirc),[\mathrm{HCl}]=0.3 \mathrm{M},[\mathrm{HA}]_{(\mathrm{o})}=0.177 \mathrm{M} ;(\triangle),[\mathrm{HCl}]=1.0 \mathrm{M},[\mathrm{HA}]_{(\mathrm{o})}=$ $0.147 \mathrm{M} ;(\square), \mathrm{HCl}=3.0 \mathrm{M},[\mathrm{HA}]_{(\mathrm{o})}=0.118 \mathrm{M}$.

From the intercepts of the lines in Figs. 2 and 3, the value of extraction equilibrium constants $\left(K_{\mathrm{ex}}\right)$ for the extraction of $\mathrm{Fe}(\mathrm{III})$ from three distinct regions of [HCl] have been evaluated and tabulated (Table 1). The average values of $\log K_{\mathrm{ex}}$ are 3.064, 3.986 and 4.621 with respective standard deviations (of $\log K_{\mathrm{ex}}$ ) of $0.136,0.067$ and 0.104 for extractions of $\mathrm{Fe}(\mathrm{III})$ from lower, intermediate and higher $\mathrm{HCl}$ concentration regions, 
respectively. The value of $\log K_{\mathrm{ex}}$ for Fe(III)-Cyanex 272 and Fe(III)-Cyanex 302 systems are -2.3 [20] and -0.632 [30], respectively. Although the extraction equilibrium constant at any $[\mathrm{HCl}]$ region is many times higher in case of Cyanex 301 than in cases of Cyanex 272 and Cyanex 302, the high extractant functionality or dependence in the present case at both high and low loadings renders low loading capacity of Cyanex 301 towards Fe(III). Consequently, Cyanex 301 comes out as a less effective commercial extractant for Fe(III).

Table 1. Elucidation of extraction equilibrium constants $\left(K_{e x}\right)$ at various aqueous acidity regions for the extraction of $\mathrm{Fe}(\mathrm{III})$ by Cyanex 301 at $303 \mathrm{~K}$.

\begin{tabular}{|c|c|c|c|c|c|c|}
\hline Fig. No. & $\begin{array}{c}\text { Constant } \\
{[\mathrm{HCl}]_{(\mathrm{eq})}, \mathrm{M}}\end{array}$ & $\begin{array}{c}\text { Constant } \\
\text { [Cyanex301] }_{(\mathrm{eq})}, \mathrm{M}\end{array}$ & $\begin{array}{c}\text { Intercept, } \\
I\end{array}$ & $\begin{array}{l}\log \\
K_{\mathrm{ex}}\end{array}$ & $\begin{array}{c}\text { Average } \\
\log K_{\text {ex }}\end{array}$ & $\begin{array}{l}\text { St. dev of } \\
\log K_{\mathrm{ex}}\end{array}$ \\
\hline \multicolumn{7}{|c|}{ (i) $[\mathrm{HCl}]<0.4 \mathrm{M}$} \\
\hline \multirow[t]{3}{*}{$2^{(a)}$} & variable & 0.177 & 0.744 & 3.000 & & \\
\hline & & 0.118 & 0.232 & 3.016 & 3.064 & 0.136 \\
\hline & & 0.059 & -0.392 & 3.295 & & \\
\hline $3^{(\mathrm{b})}$ & 0.3 & variable & 4.514 & 2.945 & & \\
\hline \multicolumn{7}{|c|}{ (ii) $[\mathrm{HCl}]=0.7-2.0 \mathrm{M}$} \\
\hline \multirow[t]{3}{*}{$2^{(a)}$} & variable & 0.177 & 1.779 & 4.035 & & \\
\hline & & 0.118 & 1.257 & 4.042 & 3.986 & 0.067 \\
\hline & & 0.059 & 0.304 & 3.991 & & \\
\hline $3^{(\mathrm{b})}$ & 1.0 & variable & 3.875 & 3.875 & & \\
\hline \multicolumn{7}{|c|}{ (iii) $[\mathrm{HCl}]>3 \mathrm{M}$} \\
\hline \multirow[t]{3}{*}{$2^{(\mathrm{a})}$} & variable & 0.177 & 2.487 & 4.743 & & \\
\hline & & 0.118 & 1.902 & 4.686 & 4.621 & 0.104 \\
\hline & & 0.059 & 0.896 & 4.583 & & \\
\hline $3^{(\mathrm{b})}$ & 5.0 & variable & 3.352 & 4.470 & & \\
\hline
\end{tabular}

${ }^{\text {(a) }} \log K_{\mathrm{ex}}=I-3 \log [\text { Cyanex 301 }]_{\mathrm{eq}}$

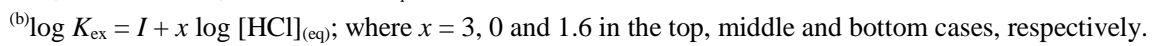

The strippings of $\mathrm{Fe}(\mathrm{III})$ from the organic phase (extracted at various aqueous acidities) by various acid solutions have been investigated and the results have been tabulated (Table 2). It is seen that 1 or $6 \mathrm{M}$ mineral acids alone $\left(\mathrm{H}_{2} \mathrm{SO}_{4} /\right.$ $\mathrm{HNO}_{3} / \mathrm{HClO}_{4} / \mathrm{HCl}$ ) are not good stripping agents for bringing back Fe(III) from the extracted complexes formed at various aqueous acidities even when the organic phases do not contain practically no free extractant. However, the mixed stripping agent consisting of $6 \mathrm{M} \mathrm{H}_{2} \mathrm{SO}_{4}$ and $1 \mathrm{M} \mathrm{Na}_{2} \mathrm{C}_{2} \mathrm{O}_{4}$ is found to be effective for stripping, which can strip $60 \% \mathrm{Fe}(\mathrm{III})$ in single stage and cumulative $\sim 99 \% \mathrm{Fe}(\mathrm{III})$ in the $4^{\text {th }}$ stage of stripping. It is also noticed that stripping of $\mathrm{Fe}(\mathrm{III})$ from $\mathrm{FeA}_{3}$ (formed at $[\mathrm{HCl}]=0.3 \mathrm{M}$ ) is little more difficult than from $\mathrm{FeCl}_{3} .3 \mathrm{HA}$ (formed at $[\mathrm{HCl}]=1$ and $3 \mathrm{M}$ ). It is therefore recommended to use $6 \mathrm{M} \mathrm{H}_{2} \mathrm{SO}_{4}$ and $1 \mathrm{M} \mathrm{Na}_{2} \mathrm{C}_{2} \mathrm{O}_{4}$ mixture as stripping agent. 
Table 2. Data for stripping of extracted Fe(III)-Cyanex 301 complex from kerosene phase by various acid solution.

$[\mathrm{Fe}(\mathrm{III})]_{(0, \text { ini })}=1 \mathrm{~g} / \mathrm{L},[\mathrm{HA}]_{(0, \text { ini) }}=\sim 0 \mathrm{M}$, organic to aqueous phase $(\mathrm{O} / \mathrm{A})$ ratio $=1$, Temp. $=303 \mathrm{~K}$, time $=1 \mathrm{~h}$.

\begin{tabular}{lccccc}
\hline Stripping agent & $\begin{array}{l}\text { Conc. of } \\
\text { stripping }\end{array}$ & $\begin{array}{l}\text { Stage } \\
\text { agent, } \mathrm{M}\end{array}$ & & \multicolumn{3}{c}{ \% Fe(III) stripped from complex formed at } \\
\cline { 4 - 6 } & 1 & 1 & 5.85 & 7.20 & 7.15 \\
\hline $\mathrm{H}_{2} \mathrm{SO}_{4}$ & 1 & 1 & 6.00 & 6.90 & 6.95 \\
$\mathrm{HNO}_{3}$ & 1 & 1 & 6.45 & 7.50 & 7.40 \\
$\mathrm{HClO}_{4}$ & 1 & 1 & 4.80 & 5.05 & 5.10 \\
$\mathrm{HCl}$ & 6 & 1 & 13.70 & 15.20 & 15.00 \\
$\mathrm{H}_{2} \mathrm{SO}_{4}$ & 6 & 1 & 14.00 & 15.00 & 15.00 \\
$\mathrm{HNO}_{3}$ & 6 & 1 & 16.20 & 16.50 & 17.00 \\
$\mathrm{HClO}_{4}$ & 6 & 1 & 12.30 & 12.80 & 12.90 \\
$\mathrm{HCl}$ & $(6+1)$ & 1 & 55 & 62.00 & 62.50 \\
$\mathrm{H}_{2} \mathrm{SO}_{4}+\mathrm{Na}_{2} \mathrm{C}_{2} \mathrm{O}_{4}$ & & 2 & 78 & 84.00 & 86.00 \\
& & 3 & 90 & 94.00 & 95.80 \\
& & 4 & 96 & 99.00 & 99.50 \\
\hline
\end{tabular}

\section{Conclusion}

The following conclusions can be drawn:

i) Cyanex 301 can effectively extract Fe(III) from chloride solution. The equilibration time is $1 \mathrm{~h}$.

ii) The extent of extraction is independent of the initial Fe(III) concentration in the aqueous phase provided equilibrium aqueous acidity and Cyanex 301 concentration are kept constant.

iii) The breaks in $[\mathrm{HCl}]$ dependence curve indicate three types of extraction reactions depending on the $[\mathrm{HCl}]$ prevailing in the system. The $[\mathrm{HCl}]$ dependences are $-3, \sim 0$ and -1.6 in its lower, intermediate and higher concentration regions, respectively. The extractant dependence is always 3.

iv) Both $[\mathrm{HCl}]$ and $[\mathrm{HA}]$ dependencies of 3 but of opposite sign suggest that the extraction occurs via the reaction: $\mathrm{Fe}^{3+}+3 \mathrm{HA}_{(\mathrm{o})} \rightleftharpoons \mathrm{FeA}_{3 \text { (o) }}+3 \mathrm{H}^{+}$with the value of extraction equilibrium constant $\left(K_{\mathrm{ex}}\right)$ of $10^{3.064}$ in the low $[\mathrm{HCl}]$ region.

v) At intermediate $[\mathrm{HCl}]$ region, the $[\mathrm{HCl}]$ dependence of $\sim 0$ and $[\mathrm{HA}]$ dependence of 3 leads to the conclusion that the extraction under this condition occurs via the reaction: $\mathrm{FeCl}_{3}+3 \mathrm{HA}_{(\mathrm{o})} \rightleftharpoons \mathrm{FeCl}_{3} \cdot 3 \mathrm{HA}_{(\mathrm{o})}$ with $K_{\mathrm{ex}}$ value of $10^{3.986}$.

vi) At higher $[\mathrm{HCl}]$ region, the extraction proceeds via reaction: $\mathrm{HFeCl}_{4}+3 \mathrm{HA}_{(\mathrm{o})}$ $\rightleftharpoons \mathrm{FeCl}_{3} \cdot 3 \mathrm{HA}_{(\mathrm{o})}+\mathrm{HCl}$ with $K_{\mathrm{ex}}$ value of $10^{4.621}$.

vii) The extraction is found to depend on $\mathrm{Cl}^{-}$concentration because of changes in the \% composition of $\mathrm{Fe}(\mathrm{III})-\mathrm{Cl}^{-}$species in the aqueous phase. 
viii) The loading capacities are estimated to be $5.50 \mathrm{~g}$ Fe(III)/100 g Cyanex 301 at all aqueous acidities giving the Cyanex 301 to $\mathrm{Fe}(\mathrm{III})$ ratio in the loaded or saturated complex is 3 . The mechanism or the composition of the extracted species at low loading remains unaltered at high loading.

ix) The extraction processes at all acidities are endothermic in nature and the value of $\Delta H$ is $45.2,12.0$ and $16.2 \mathrm{~kJ} / \mathrm{mol}$ at lower, intermediate and higher [ $\mathrm{HCl}$ ] regions, respectively.

x) $6 \mathrm{M} \mathrm{H}_{2} \mathrm{SO}_{4}$ and $1 \mathrm{M} \mathrm{Na}_{2} \mathrm{C}_{2} \mathrm{O}_{4}$ mixture is found to strip $60 \% \mathrm{Fe}(\mathrm{III})$ in single stage and cumulative $99 \%$ in the fourth stage.

\section{References}

1. M. R. Ali, R. K. Biswas, M. A. Habib, and D. K. Sarker, Rajshahi University Studies. Part B. Journal of Science 31, 21 (2003).

2. K. C. Sole and J. B. Hiskey, Hydrometallurgy 30, 345 (1992). doi:10.1016/0304-386X(92)90093-F

4. T. Sekine and Y. Hasegawa, Solvent Extraction Chemistry: Fundamentals and Applications (Marcel Dekker Inc., NewYork, 1977).

5. M. F. Islam and R. K. Biswas, J. Inorg. Nucl. Chem. 43, 1929 (1981). doi:10.1016/0022-1902(81)80413-7

5. J. W. Roddy, C. F. Coleman, and S. Arai, J. Inorg. Nucl. Chem. 33, 1090 (1971). doi:10.1016/0022-1902(71)80179-3

6. S. M. Karpacheva and L. V. Ilozheva, Radiokhimiya (Eng.) 11, 32 (1969).

7. C. F.Baes and H. T. Baker Jr., J. Phys. Chem. 64, 89 (1960). doi:10.1021/j100830a022

8. T. Sato, T. Nakamura and M. Ikeno, Hydrometallurgy 15, 209 (1985). doi:10.1016/0304-386X(85)90055-6

9. T. Sato, T. Nakamura and M. Ikeno, Denki Kagaku Oyobi Kogyo Bustsuri Kagaku 53, 314 (1985).

10. R. K. Biswas and F. Islam, J. Bang. Acad. Sc. 6, 101 (1982).

11. R. K. Biswas and M. F. Islam, J. Bang. Acad. Sc. 9, 189 (1985).

12. R. K. Biswas and D. A. Begum, Hydrometallurgy 50, 153 (1998). doi:10.1016/S0304-386X(98)00048-6

13. R. K. Biswas and D. A. Begum, Hydrometallurgy 54, 1 (1999). doi:10.1016/S0304-386X(99)00043-2

14. R. K. Biswas and D. A.Begum, Hydrometallurgy 60, 81 (2001). doi:10.1016/S0304-386X(00)00191-2

15. R. K. Biswas, M. R. Ali, and N. Begum, Pak. J. Sci. Ind. Res. 50, 10 (2007).

16. G. P. Demopoulos and G. Pouskouleli, Can. Metall. Q. 28, 13 (1989).

17. F. T. Principe and G. P. Demopoulos, EPD Congress, B. Mishra (Ed) (TMS,Warrendale, 1998) pp. 267-287.

18. N. Miralles, A. M. Sastre, E. Figuerola, and M. Martinez, Hydrometallurgy 31, 1 (1992). doi:10.1016/0304-386X(92)90104-8

19. G. P. Demopoulos, I. O. Mihaylov, and G. Pouskouleli, Solvent Extr. Ion Exch. 11, 67 (1993). doi:10.1080/07366299308918146

20. R. K. Biswas and H. P. Singha, Hydrometallurgy 82, 63 (2006). doi:10.1016/j.hydromet.2006.03.002

21. R. K. Biswas, M. A. Habib, and A. K. Karmakar, Solvent Extr. Ion Exch. 25, 79 (2007). doi:10.1080/07366290601067838

22. W. A. Rickelton and R. J. Boyle, Solvent Extr. Ion Exch. 8, 783 (1990). doi:10.1080/07366299008918030 
23. M. A. Rodriguez, G. Cote, and D. Bauer, Solvent Extr. Ion Exch. 10, 811 (1992). doi:10.1080/07366299208918137

24. S. Facon, G. Cote, and D. Bauer, Solvent Extr. Ion Exch. 9, 717 (1991). doi:10.1080/07366299108918080

25. K. C. Sole and J. B. Hiskey, Hydrometallurgy 37, 129 (1995). doi:10.1016/0304-386X(94)00023-V

26. B. K. Tait, Hydrometallurgy 32, 365 (1993). doi:10.1016/0304-386X(93)90047-H

27. K. C. Sole, T. L. Ferguson and J. B. Hiskey, Solvent Extr. Ion Exch. 12, 1033 (1994). doi:10.1080/07366299408918252

28. B. R. Reddy, J. R. Kumar, and A. V. Reddy, J. Chem. Tech. Biotech. 79, 1301 (2004). doi:10.1002/jctb.1129

29. J. Bassette, R. C. Denny, G. H. Jeffery, and J. Mendham, Vogel's Text book of Quantitative Inorganic Analysis, $4^{\text {th }}$ edition, (ELBS, London, 1979) p. 741.

30. R. K. Biswas, M. R. Ali, S. M. A. Salam, A. Akhter, A. K. Karmakar and M. H. Ullah, Bang. J. Sci. Ind. Res., Communicated (2010).

31. F. Habashi, Extractive Metallurgy, Vol.4: Hydrometallurgy (Gordon and Breach, New York, 1969) p. 363.

32. G. A. Gamlen and D. O. Jordan, J. Chem. Soc. 1435 (1953). 